\title{
HAARLÄNDER, Stephanie, Rabanus Maurus zum Kennenlernen. Ein Lesebuch mit einer Einführung in sein Leben und Werk
}

Michel Jean-Louis Perrin

\section{OpenEdition}

Édition électronique

URL : http://journals.openedition.org/ifha/688

DOI : $10.4000 /$ ifha.688

ISSN : 2198-8943

Éditeur

IFRA - Institut franco-allemand (sciences historiques et sociales)

Référence électronique

Michel Jean-Louis Perrin, « HAARLÄNDER, Stephanie, Rabanus Maurus zum Kennenlernen. Ein Lesebuch mit einer Einführung in sein Leben und Werk», Revue de l'IFHA [En ligne], Date de recension, mis en ligne le 01 janvier 2006, consulté le 22 septembre 2020. URL : http://journals.openedition.org/ifha/688 ; DOI : https://doi.org/10.4000/ifha.688

Ce document a été généré automatiquement le 22 septembre 2020.

(C)IFHA 


\title{
HAARLÄNDER, Stephanie, Rabanus Maurus zum Kennenlernen. Ein Lesebuch mit einer Einführung in sein Leben und Werk
}

\author{
Michel Jean-Louis Perrin
}

Ce livre accompagne explicitement celui de Wilhelm Wilhelmy recensé plus bas (voir la seconde de couverture) ; en outre la page de couverture s'orne de la croix de fleurs qui est au centre du poème 16 de l'In honorem sancti crucis, et de Raban en prières au pied de la croix (poème 28). Le cardinal Lehmann présente (en quatrième de couverture et $p$. 9-11) le livre comme un choix de textes de Raban permettant de comprendre ce dernier : en quelque sorte, pour lui, la Bible est la mesure de toutes choses. En tant qu'abbé et qu'archevêque, il a eu le sens de la justice devant les puissances politiques, il a voulu communiquer le savoir de son temps et en tant que poète, il a été attaché aux beauxarts.

C'est ce programme que S.H. a mis en oeuvre en présentant une cinquantaine de textes divers de Raban. Ce livre est conçu comme un accompagnement du catalogue, mais pouvant être lu indépendamment de lui ; on ne s'étonnera pas de constater certaines reprises inévitables (quelques textes, des résumés bibliographiques) et on n'en fera pas grief à l'auteur. Sauf exception, les textes sont présentés en traduction, et répondent ainsi aux besoins de lecteurs lisant l'allemand plus facilement que le latin. Nous pouvons ainsi " butiner " à l'intérieur d'une oeuvre très vaste (six volumes de la Patrologie Latine) : d'abord les poésies, puis des extraits importants notamment de son oeuvre exégétique, et l'hymne pascale Veni Creator Spiritus, avec la traduction de Goethe. Raban y apparait comme un médiateur de la culture européenne, de l'Antiquité tardive, de la patristique (il est mieux qu'un compilateur), comme quelqu'un qui a « propagé » l'Église et la culture, comme quelqu'un dont la source nourricière est avant tout la Bible. S.H. a voulu rendre sensible par son choix de textes l'activité multiple de 
Raban, comme moine, abbé, archevêque, écrivain, et on peut dire qu'elle y a largement réussi.

Au début, une présentation globale de Raban : sa vie, son oeuvre, son insertion dans la politique et les controverses théologiques de son temps, avec sa proximité avec les Carolingiens (p. 13-60). Tout cela nous semble à la fois bien informé et très pédagogique ; évidemment ce n'est pas le lieu d'y chercher du nouveau.

S.W. présente donc successivement (à chaque fois avec une brève introduction) des extraits de lettres (de Raban ou d'autres sur des sujets très variés), des poèmes figurés avec leurs uersus intexti, l'enseignement spirituel de Raban, ses commentaires bibliques, le De rerum naturis, les controverses, sa prédication et le Veni Creator Spiritus. Cela occupe presque 100 pages (p. 62-158), ce qui est le coeur du livre.

Viennent ensuite un avertissement de l'éditeur, un utile tableau des œuvres et des éditions de Raban (datées quand la chose est possible), un tableau biographique (p. 172-174), une table de sigles et une bibliographie de sept pages (p. 177-183).

Au total : un très utile petit livre, à destination du grand public, certes, mais qui donne l'essentiel. Ceux qui veulent aller plus loin le peuvent grâce aux références qui sont systématiquement fournies et aux éléments bibliographiques. Là encore, on peut être reconnaissant à l'auteur et à l'évêché de Mayence d'avoir édifié ces deux monuments qui permettent de mieux connaître leur illustre compatriote.

Michel Jean-Louis PERRIN (Université de Picardie Jules-Verne, Amiens) 